\title{
Welcome by the Mayor of Valtetsi
}

Mr. Chairman

Ladies and Gentlemen

The municipality of Valtetsi welcomes you and wishes success in your work.

Arcadia is both a historical and modern region. Moreover, as a name it remained in the western culture recalling a harmonious and peaceful dream, a lost and desirable situation where the human being lived in balance with nature, a region where the person did not feel yet uprooted. For thousands of years the poetic voices retained vivid this eternal bucolic call of simplicity and accessible happiness.

Gazing the starlit sky we will always see Kallisto, the daughter of Lykaona, king of Arcadia and her son Arcadian as they were both transformed in to the constellations Major and Minor Ursus because of the erotic libido of Jupiter and the jealousy of Hera. And we will always remember Centaurus Cheirona, the great schoolteacher of ancient heroes, who was the first to name the constellations according to mythology.

Finally we would like to thank the patriot Mr. T. Tzioumi who returns to his beautiful village in Arcadia just like Antaios did. In the geographic place that inspired the arcadian ideal, such activities recall in the limelight Arcadia as was dreamed by Europe.

Mr. Chairman, ladies and gentlemen, success in your scientific work. The Municipality of Valtetsi and I myself will be always next to you so that your stay at Arcadia will always remain vivid in your memory.

Thank you.

Nikos Papanikolaou

Mayor of Valtetsi 